Sharif University of Technology
Scientia Iranica
SCIENTIA

\title{
Determination of Weibull parameters by different numerical methods and analysis of wind power density in Osmaniye, Turkey
}

\author{
Y.A. Kaplan* \\ Department of Energy Engineering, Osmaniye Korkut Ata University, 80000, Osmaniye, Turkey. \\ Received 10 November 2015; received in revised form 17 June 2016; accepted 4 July 2016
}

\author{
KEYWORDS \\ Weibull distribution; \\ Graphical method; \\ Moment method; \\ Energy trend method; \\ Energy pattern \\ method; \\ Maximum likelihood \\ method.
}

\begin{abstract}
In this study, the potential of wind energy in Osmaniye Region has been analysed statistically on the basis of information that has been measured hourly between the years 2009 to 2013. The two-parameter Weibull Distribution Function is generally applied to evaluate the potential of wind energy in any region. This study introduced the evaluation of Weibull Distribution Function parameters which are obtained by different kinds of numerical methods, namely Graphical Method (GM), Moment Method (MM), Energy Pattern Method (EPM), Energy Trend Method (ETM), and Maximum Likelihood Method (MLM). The Relative Percentage Error (RPE) of statistical test is used to compare the efficiency of all used methods. The calculated power density of all used numerical methods is a major key issue for suitability use of wind energy. The evaluation of Weibull parameters and wind power distribution play a crucial role in producing electricity from wind power. The results of the used methods are compared, and the obtained pre-research results show that the wind energy potential in Osmaniye Region is statistically suitable for electricity production.

(C) 2017 Sharif University of Technology. All rights reserved.
\end{abstract}

\section{Introduction}

Nowadays, the need of energy is increasing day by day due to the population growth and the advancements of technology [1]. Hence, the search for new energy resources becomes a very important subject for the entire world [2]. Energy is the most important factor which affects economic structure of a country. As is known, energy is seen as not only the internal dynamics of the countries, but also as a strategic case which affects International Relations, including political as well as military conflicts. Energy is also the primary element of economic and social development in the world $[3,4]$. In recent years, renewable generations,

\footnotetext{
*.E-mail address: alperkaplan@osmaniye.edu.tr
}

especially wind power and photovoltaic (PV) systems, have been increasingly used in power systems $[5,6]$. Wind energy has been used in irrigation, wheatgrinding, vessels, and many other fields because it is an environmentally-friendly future energy resource. Furthermore, wind energy is used for meeting the energy requirement that will be the most important problem of the future world. They are also powerful political players, thanks to the economic power. Currently, wind energy is seen as a positive alternative to fossil fuels and also a way to assist the expansion of local economies in future. The world will use renewable energy instead of using fossil fuels in order to meet the demands of the world's energy $[7,8]$. The consumption of fossil fuels has negative environmental impacts, particularly the release of carbon dioxide $\left(\mathrm{CO}_{2}\right)$ and other harmful gases into the atmosphere. $\mathrm{CO}_{2}$ emissions can be greatly reduced through the use of renewable energy 
resources [9]. Wind consists of the temperature and pressure difference that is resulted from heating and cooling of the atmosphere. It is estimated that almost $2 \%$ of all sun energy that the world gets is converted into the kinetic energy of wind. When it is considered that this quantity is the thousands of times of the world's total energy consumption, the significance of wind energy can be understood. Wind energy depends on the wind speed. Speed of wind changes with the height, and power of wind changes with the cube of wind speed. There are many studies related to wind energy subject, and the speed of the wind is taken as a random parameter. The most common distribution function to define the wind speed variation is Weibull distribution function. This study aims to determine the wind energy potential in Osmaniye. We have collected the five-year data of the wind speed measured at 10-meter height from the General Directorate of State Meteorology. Kantar and Usta [10] analyzed the use of the minimum cross entropy principle in the estimation of wind speed distribution and wind power density functions. Moreover, they compared the Weibull pdf (probability density function) with the MinxEnt (minimum cross-entropy principle) pdfs. Akda $\breve{g}$ and Dinler [11] reviewed different methods, i.e. the graphical, maximum likelihood, moment methods, and energy pattern method. Bilgili and Şahin [12] investigated wind energy density in the southern and southwestern regions of Turkey using the Weibull and Rayleigh probability density functions. Rocha et al. [13] dealt with the evaluation and comparison of different numerical methods for the assessment of efficiency in determining the parameters for the Weibull distribution function, using wind speed data collected in Camocim and Paracuru cities. Freitas et al. [14] introduced a new approach for analyzing numerical methods used in calculating the Weibull distribution parameters for the prediction of wind energy source. Chang [15] reviewed six kinds of numerical methods, commonly used for estimating Weibull parameters. Bilir et al. [16] collected wind data for a year between June 2012 to June 2013. Wind speed data, collected for two different heights $(20 \mathrm{~m}$ and $30 \mathrm{~m}$ ) from a measurement station installed in Atılım University campus area (Ankara, Turkey), were recorded using a data logger as one-minute average values. They determined 1 shape $(k)$ and scale $(c)$ parameters of Weibull using five different methods. The Weibull distribution function has been generally used to assess wind energy potential. Yaniktepe et al. [17] investigated the wind energy potential in Osmaniye for a period of 44 months, from January 2008 to August 2011. They used the graphical method to determine the coefficients of Weibull distribution function. In this present study, five different methods were used to determine the coefficients of Weibull distribution method for a period of five years, and also the calculated average wind speed and power density of all used numerical methods were compared to the real data. The Weibull distribution function has two parameters which are dimensionless shape parameters ' $k$ ' and scale ' $c$ '. These parameters must be calculated to determine the average wind speed and wind power density.

\section{Statistical analysis of wind energy}

Firstly, it is necessary to determine wind power potential to benefit from wind energy. It is well known that the power of the wind energy depends on wind velocity ' $v$ ', blade swept area of wind turbine ' $A$ ', and air density of region ' $\rho$ '; plus, the power of wind energy is given in the following equation [10]:

$$
P_{A}=\frac{1}{2} \rho A v^{3}
$$

As seen, wind speed is the most important input in order to determine the power potential. Wind direction plays an important role in the placement of wind power conversion systems, excluding the effective potential. In order to identify a region of the wind power potential, it is required for wind velocity values to be measured at specific time intervals. To do this, measurements of meteorological stations and airports can be utilized.

\subsection{Weibull distribution function}

In practice, a variety of methods have been utilized to determine the wind energy of a region. A wind speed distribution measure or a frequency distribution is used to determine the wind energy potential of a specific region, if possible. If not, wind speed distribution can be demonstrated through other analytical distribution functions. There are many distribution functions to determine the dispersion of wind speed for any region. One of these functions is the Weibull distribution function. This distribution is not only quite flexible and simple, but it also complies with real data. In other words, as Weibull distribution complies with the wind speed data, it is generally accepted in wind energy analyses [18]. Firstly, as shown in Table 1, a specific frequency range of wind speed (the number of blowing) and the probability are obtained. In the second column of Table 1, wind speeds are grouped periodically. The third column gives the average wind speed for each speed ratio. The number of blowing each speed ratio or frequency is shown in the fourth column. The probability density is located in the fifth column of the table. The cumulative probability density function is given in the sixth column.

Probability density of each speed ratio is given in the following equation: 
Table 1. Frequency and probability schemes of hourly wind speed between the years 2009 to 2013.

\begin{tabular}{cccccc}
\hline $\mathbf{2 0 0 9 - 2 0 1 3}$ & $\boldsymbol{v}_{\boldsymbol{i}}(\mathbf{m} / \mathbf{s})$ & $\boldsymbol{v}_{\boldsymbol{i}}^{*}(\mathbf{m} / \mathbf{s})$ & $\boldsymbol{f i}$ & $\boldsymbol{p}\left(\boldsymbol{v}_{\boldsymbol{i}}\right)$ & $\boldsymbol{P}\left(\boldsymbol{v}_{\boldsymbol{i}}\right)$ \\
\hline 1 & $0-1$ & 0.5 & 9735 & 0.229957 & 0.229957 \\
2 & $1-2$ & 1.5 & 14211 & 0.335688 & 0.565645 \\
3 & $2-3$ & 2.5 & 7903 & 0.186682 & 0.752327 \\
4 & $3-4$ & 3.5 & 3335 & 0.078778 & 0.831105 \\
5 & $4-5$ & 4.5 & 2607 & 0.061582 & 0.892687 \\
6 & $5-6$ & 5.5 & 2216 & 0.052346 & 0.945032 \\
7 & $6-7$ & 6.5 & 1230 & 0.029055 & 0.974087 \\
8 & $7-8$ & 7.5 & 577 & 0.01363 & 0.987717 \\
9 & $8-9$ & 8.5 & 273 & 0.006449 & 0.994165 \\
10 & $9-10$ & 9.5 & 112 & 0.002646 & 0.996811 \\
11 & $10-11$ & 10.5 & 80 & 0.00189 & 0.998701 \\
12 & $11-12$ & 11.5 & 40 & 0.000945 & 0.999646 \\
13 & $12-13$ & 12.5 & 11 & 0.00026 & 0.999906 \\
14 & $13-14$ & 13.5 & 4 & $9.45 \mathrm{E}-05$ & 1 \\
\hline
\end{tabular}

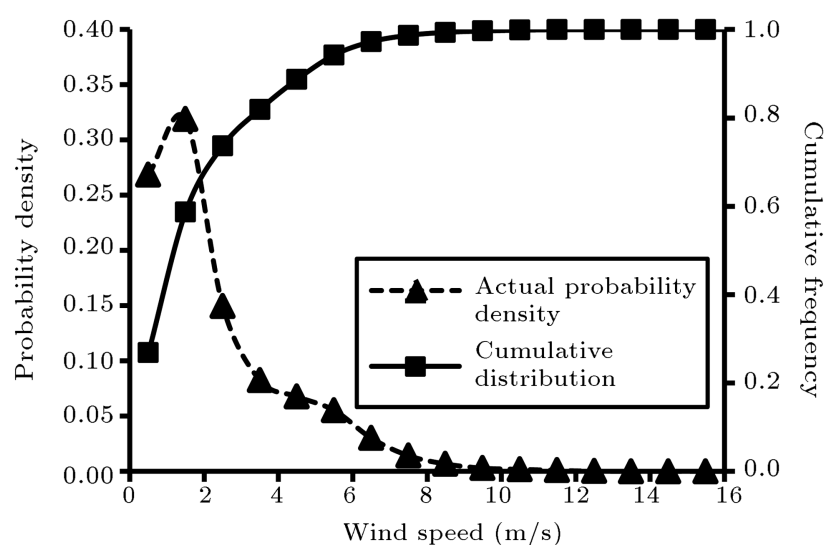

Figure 1. Probability density and cumulative probability distributions of wind speed.

$$
p\left(v_{i}\right)=\frac{f_{i}}{\sum_{i=1}^{N} f_{i}} .
$$

The cumulated probability density, which is given in the following equation, is illustrated in the sixth column of the table $[19,20]$ :

$$
P\left(v_{i}\right)=\sum_{i=1}^{N} p\left(v_{i}\right)
$$

The obtained probability density and the cumulative probability distributions of wind speed ranges are given in Figure 1.

The general expression of the two-parameter Weibull is given by:

$$
p(v)=\left(\frac{k}{c}\right)\left(\frac{v}{c}\right)^{k-1} \exp \left[-\left(\frac{v}{c}\right)^{k}\right] .
$$

The cumulative function of wind speed can be attained by computing the integral of the probability density function given by:

$$
p(v)=1-\exp \left[-\left(\frac{v}{c}\right)^{k}\right],
$$

where $p(v)$ is the observed probability density function, $P(v)$ is the cumulative probability density function, shape $(k)$ and scale $(c)$ are the parameters of Weibull distribution function [21,22].

\section{Determination of Weibull parameters}

There are many methods to determine shape parameter " $k$ " and scale parameter " $c$ " of Weibull distribution Function. In this work, there are five popular methods used to determine Weibull parameters; these are:

- Graphical method;

- Moment method;

- Energy trend method;

- Energy pattern method;

- Maximum likelihood method.

The Weibull distribution function, which is a three-parameter function, known for wind speed though, can be expressed mathematically in a twoparameter model.

\subsection{Graphical methods}

In this method, the least squared regression is used to determine parameters $k$ and $c$. By taking twice logarithm of the general expression of Weibull distribution function, the graphical method is obtained as follows:

$$
\begin{aligned}
& -\left(\frac{v}{c}\right)^{k}=\ln [1-P(v)], \\
& k \ln (v)-k \ln (c)=\ln [-\ln [1-P(v)]],
\end{aligned}
$$

this equation is found. Here, $x=\ln (v), y=\ln [-\ln [1-$ 
Table 2. Hourly speed of wind's $x_{i}$ and $y_{i}$ schemes.

\begin{tabular}{cc}
\hline $\boldsymbol{x}_{\boldsymbol{i}}=\ln \left(\boldsymbol{v}_{\boldsymbol{i}}\right)$ & $\boldsymbol{y}_{\boldsymbol{i}}=\ln \left[-\boldsymbol{\operatorname { l n }}\left[\mathbf{1}-\boldsymbol{P}\left(\boldsymbol{v}_{\boldsymbol{i}}\right)\right]\right]$ \\
\hline-0.69315 & -1.34205 \\
0.405465 & -0.18165 \\
0.916291 & 0.333357 \\
1.252763 & 0.575758 \\
1.504077 & 0.802899 \\
1.704748 & 1.065059 \\
1.871802 & 1.295552 \\
2.014903 & 1.481495 \\
2.140066 & 1.637823 \\
2.251292 & 1.748864 \\
2.351375 & 1.894017 \\
2.442347 & 2.07258 \\
2.525729 & 2.226465 \\
\hline
\end{tabular}

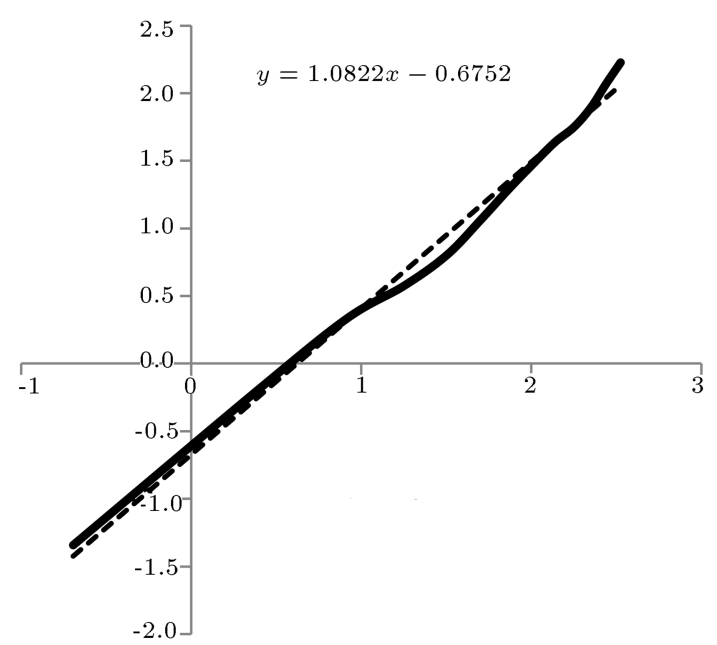

Figure 2. Linear equation of graphic method.

$P(v)]], A=k$, and $B=-k \ln (c)$, and $y=A x+B$ are accepted; there is a form of linear equations, and also this expression is obtained from $B=-k \ln (c)$ and $c=\exp (-B / A)[10,12]$. The values of ' $x$ ' and ' $y$ ' can be calculated by Table 2 , and linear equation is obtained from what is shown in Figure 2.

The numerical values of $A$ and $B, y=A x+B$, are determined as Weibull parameters $k$ and $c$ :

$$
k=A, \quad c=\exp \left(\frac{-B}{A}\right) .
$$

Calculated parameters ' $k$ ' and ' $c$ ' for Graphical method are shown in Figures 3 and 4, respectively.

\subsection{Moment methods}

Moment method is one of the oldest methods used to determine Weibull distribution parameters. Moment method is a method where data distribution allows a solution of the relationship between average and standard deviation values, with these values being between the shape parameters using numerical methods for determining the scale of 1 to 10 and the

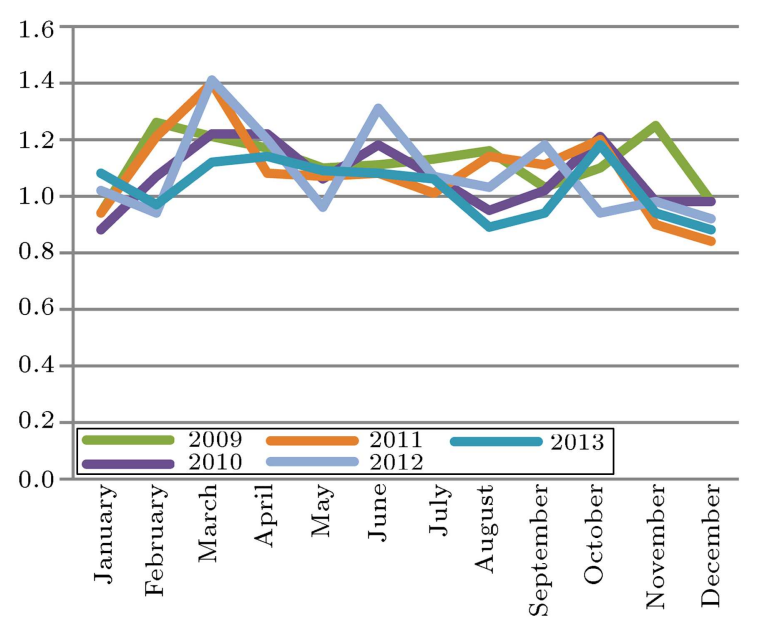

Figure 3. Parameter " $k$ " for graphical method.

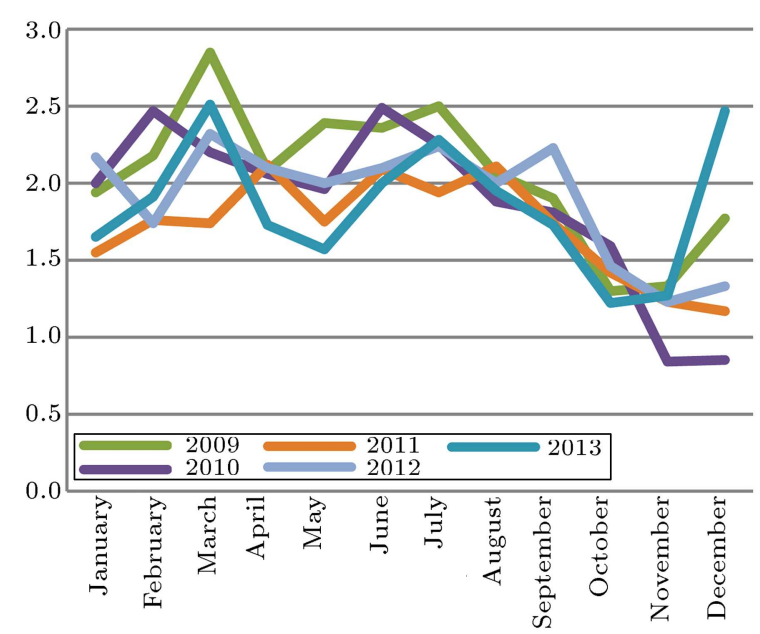

Figure 4. Parameter " $c(\mathrm{~m} / \mathrm{s})$ " for graphical method.

shape parameter. Shape and scale parameters can be expressed as in Eqs. (9) and (10) [14,23]:

$$
\begin{aligned}
& k=\left(\frac{\sigma}{v_{m}}\right)^{-1,086}, \\
& c=\frac{v_{m}}{\Gamma\left(1+\frac{1}{k}\right)},
\end{aligned}
$$

where $\Gamma$ is Gamma function. In the following equations, $\sigma$ shows standard deviation, and $v_{m}$ shows average speed:

$$
\begin{aligned}
& v_{m}=\frac{1}{n} \sum_{i=1}^{n} v_{i}, \\
& \sigma=\sqrt{\frac{1}{n} \sum_{i=1}^{n}\left(v_{i}-v_{m}\right)^{2} .}
\end{aligned}
$$

Calculated parameters ' $k$ ' and ' $c$ ' for Moment Method are shown in Figures 5 and 6 , respectively. 


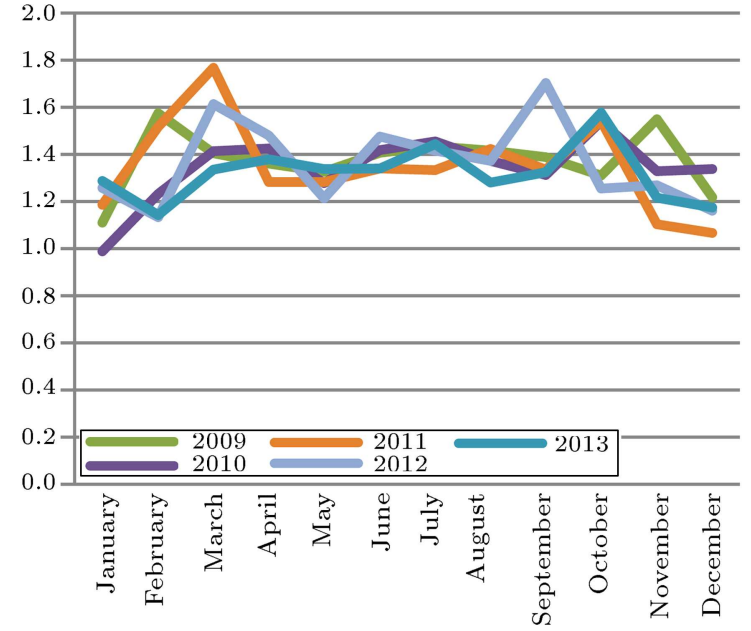

Figure 5. Parameter " $k$ " for moment method.

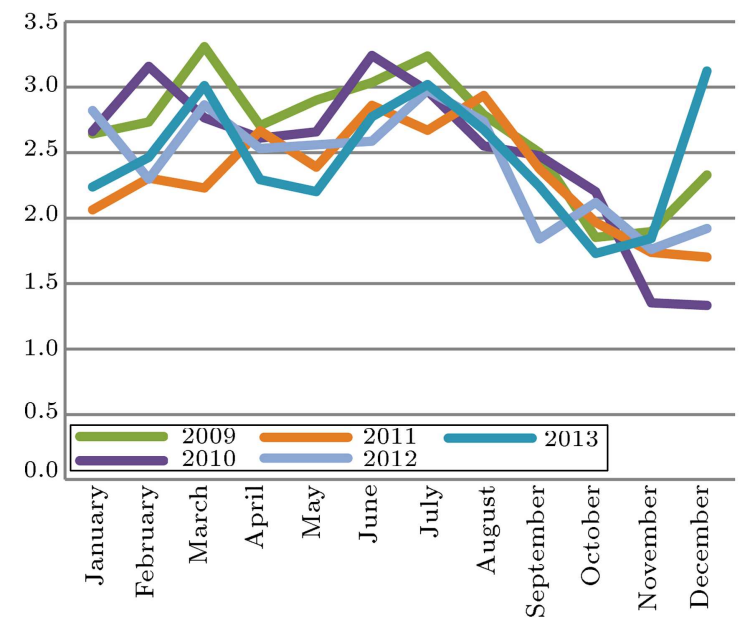

Figure 6. Parameter " $c(\mathrm{~m} / \mathrm{s})$ " for moment method.

\subsection{Energy trend method}

Energy pattern factor $E_{P F}$ is defined as wind energy obtained by the ratio of total wind energy to the average wind speed. In this method, parameters ' $k$ ' and ' $c$ ' can be easily calculated by using $E_{P F}[11]$ :

$$
\begin{aligned}
& E_{P F}=\frac{\frac{1}{n} \sum_{1}^{n} V_{i}^{3}}{\left(\frac{1}{n} \sum_{1}^{n} V_{i}\right)^{3}}, \\
& k=\frac{1}{3,9557 E_{P F}^{0,898}} .
\end{aligned}
$$

The scale parameter is calculated as follows:

$$
c=\left(\frac{1}{n} \sum_{1}^{n} V_{i}^{k}\right)^{1 / k}
$$

Calculated parameters ' $k$ ' and ' $c$ ' for energy trend method are shown in Figures 7 and 8, respectively.

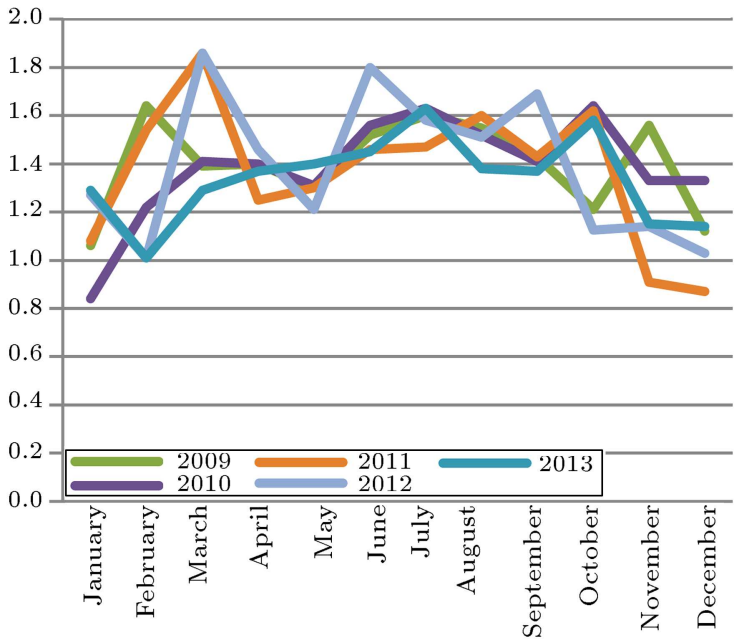

Figure 7. Parameter " $k$ " for energy trend method.

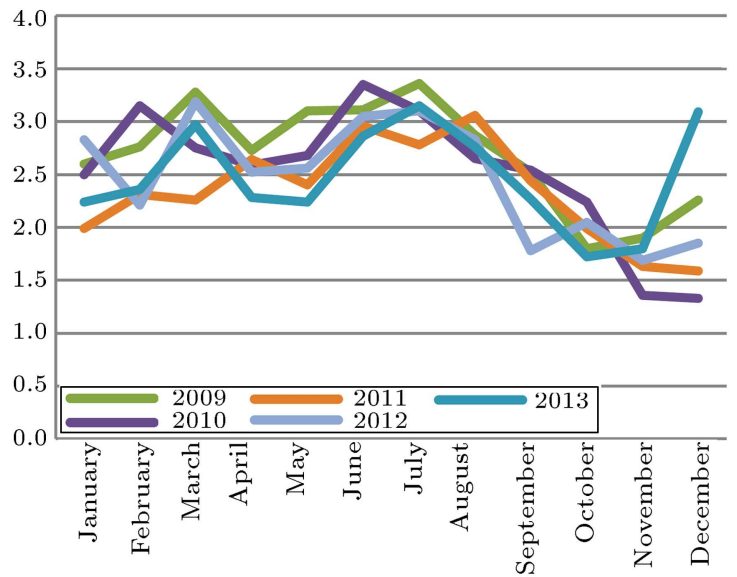

Figure 8. Parameter " $c(\mathrm{~m} / \mathrm{s})$ " for energy trend method.

\subsection{Energy pattern method}

Energy pattern factor is defined as wind energy obtained by the ratio of total wind energy to the average wind speed. After calculating energy tendency factor $\left(E_{P F}\right)$, shape parameter $(k)$ can be obtained and then parameter $(c)$ can be calculated, using average wind speed $[13,15]$ :

$$
\begin{aligned}
& E_{P F}=\frac{\frac{1}{n} \sum_{1}^{n} V_{i}^{3}}{\left(\frac{1}{n} \sum_{1}^{n} V_{i}\right)^{3}}, \\
& k=1+\frac{3,69}{E_{P F}^{2}}, \\
& c=\frac{v_{m}}{\Gamma\left(1+\frac{1}{k}\right)} .
\end{aligned}
$$

Calculated parameters ' $k$ ' and ' $c$ ' for energy pattern method are shown in Figures 9 and 10, respectively.

\subsection{Maximum likelihood method}

The maximum likelihood estimation method is a mathematical expression recognized as a likelihood function 


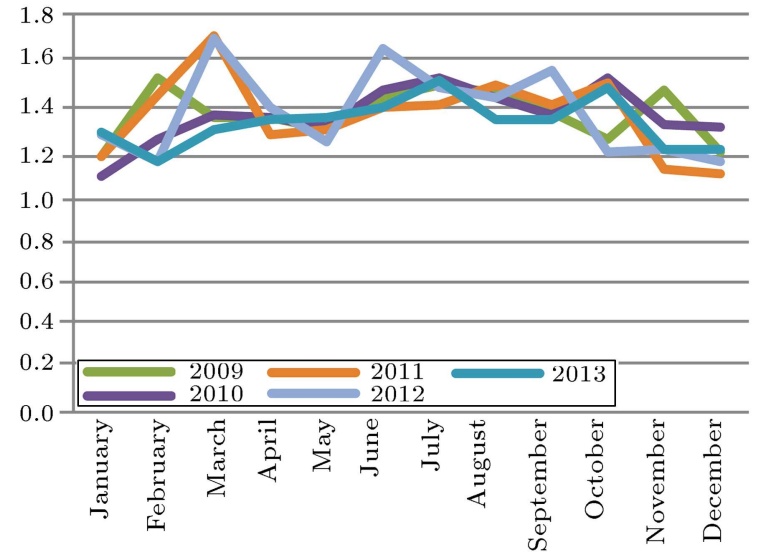

Figure 9. Parameter " $k$ " for energy pattern method.

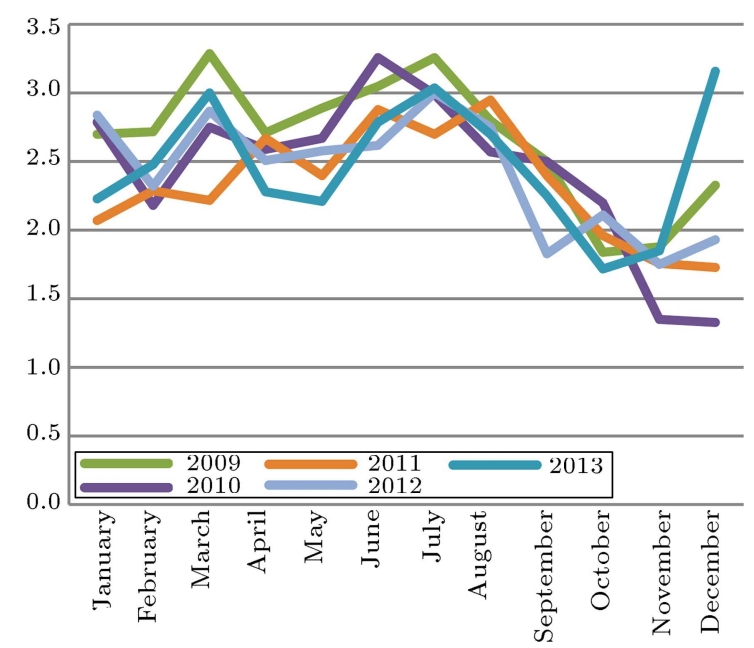

Figure 10. Parameter " $c(\mathrm{~m} / \mathrm{s})$ " for energy pattern method.

of the wind speed data in time series format. In this method, many numerical iterations can be required to determine parameters $k$ and $c$ of the Weibull function. In this method, values of Weibull parameters $k$ and $c$ are calculated by the following equation $[13,15,16]$ :

$$
\begin{aligned}
& k=\left(\frac{\sum_{1}^{n} v_{i}^{k} \ln \left(v_{i}\right)}{\sum_{1}^{n} v_{i}^{k}}-\frac{\sum_{1}^{n} \ln \left(v_{i}\right)}{n}\right)^{-1}, \\
& c=\left(\frac{1}{n} \sum_{1}^{n} V_{i}^{k}\right)^{1 / k} .
\end{aligned}
$$

Calculated parameters ' $k$ ' and ' $c$ ' for maximum likelihood method are shown in Figures 11 and 12, respectively.

\section{The obtained results}

Weibull distribution function was investigated based on the data measured hourly between the years 2009-2013, derived from the measuring stations of Osmaniye State Meteorology Affairs of General Directorate. Weibul

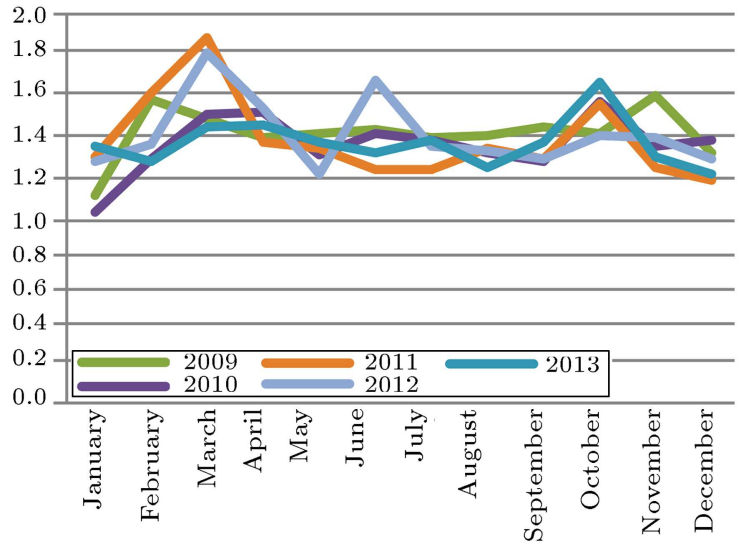

Figure 11. Parameter " $k$ " for maximum likelihood method.

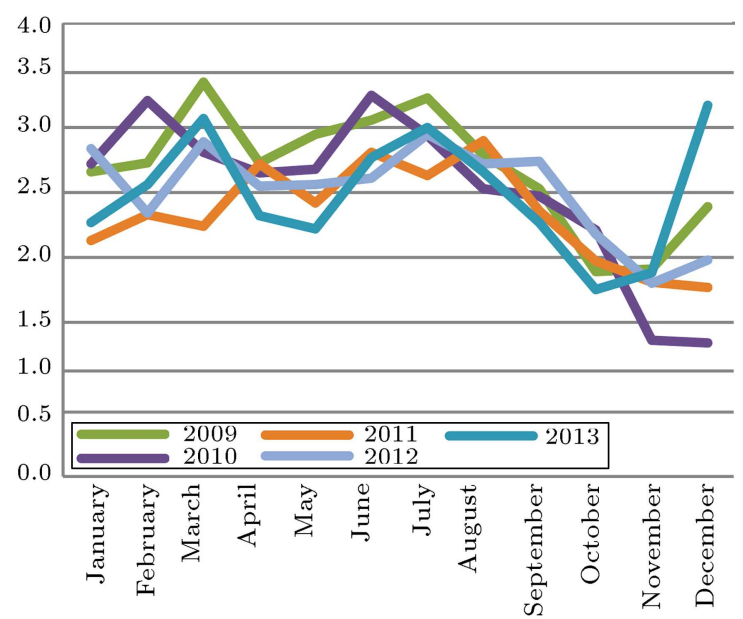

Figure 12. Parameter " $c(\mathrm{~m} / \mathrm{s})$ " for maximum likelihood method.

parameters ' $k$ ' and ' $c$ ' are computed for all methods in the mentioned period, and the obtained results are given in Table 3 .

The average wind speed ' $V_{m}$ ' and wind power density ' $P_{M}$ ' can be computed by the following equations for real-time series of data:

$$
\begin{aligned}
& v_{m}=\frac{1}{n} \sum_{i=1}^{n} v_{i}, \\
& P_{M}=\frac{1}{2} \rho \overline{V^{3}} .
\end{aligned}
$$

The average wind speed ' $V_{m}$ ' and wind power density ' $P_{W}$ ' of Weibull Distribution Function can be estimated by the following equations:

$$
\begin{aligned}
& V_{m}=c \Gamma\left(1+\frac{1}{k}\right), \\
& P_{w}=\frac{1}{2} \rho c^{3} \Gamma\left(1+\frac{3}{k}\right) .
\end{aligned}
$$

The average wind speed and wind power density for all methods are given in Figures 13 and 14 . 
Table 3. Weibull parameters for all used methods.

\begin{tabular}{|c|c|c|c|c|c|c|c|}
\hline Methods & Years & 2009 & 2010 & 2011 & 2012 & 2013 & $2009-2013$ \\
\hline \multirow{2}{*}{ Graphic method } & $k$ & 1.12 & 1.05 & 1.10 & 1.10 & 1.05 & 1.055 \\
\hline & $c(\mathrm{~m} / \mathrm{s})$ & 2.04 & 1.93 & 1.72 & 1.74 & 1.83 & 1.851 \\
\hline \multirow{2}{*}{ Moment method } & $k$ & 1.32 & 1.23 & 1.30 & 1.41 & 1.23 & 1.266 \\
\hline & $c(\mathrm{~m} / \mathrm{s})$ & 2.65 & 2.57 & 2.32 & 2.36 & 2.44 & 2.466 \\
\hline \multirow{2}{*}{ Energy trend method } & $k$ & 1.30 & 1.17 & 1.28 & 1.27 & 1.20 & 1.260 \\
\hline & $c(\mathrm{~m} / \mathrm{s})$ & 2.64 & 2.53 & 2.31 & 2.12 & 2.49 & 2.410 \\
\hline \multirow{2}{*}{ Energy pattern factor } & $k$ & 1.31 & 1.25 & 1.30 & 1.25 & 1.31 & 1.288 \\
\hline & $c(\mathrm{~m} / \mathrm{s})$ & 2.65 & 2.58 & 2.32 & 2.23 & 2.48 & 2.475 \\
\hline \multirow{2}{*}{ Maximum likelihood method } & $k$ & 1.21 & 1.07 & 1.37 & 1.87 & 1.43 & 1.320 \\
\hline & $c(\mathrm{~m} / \mathrm{s})$ & 2.58 & 2.45 & 2.37 & 2.64 & 2.57 & 2.498 \\
\hline
\end{tabular}

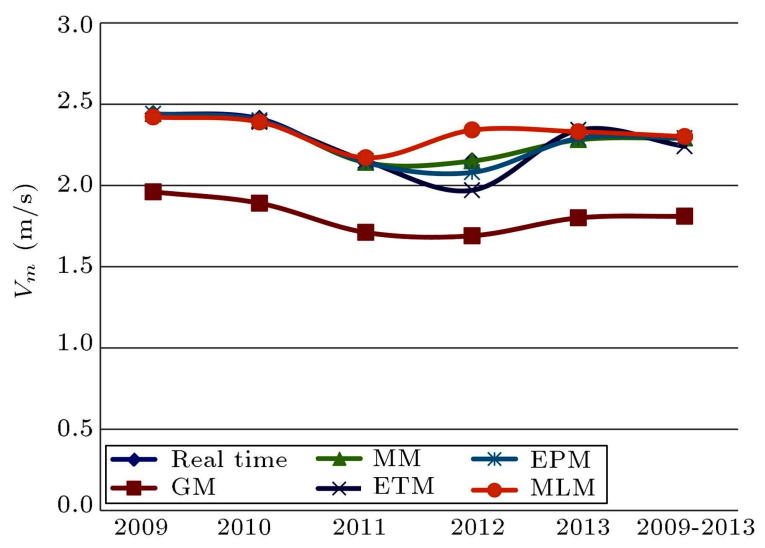

Figure 13. The mean wind speeds for all used methods.

\subsection{Statistical error analysis}

To determine the efficiency of the used methods and to find the best method of the mentioned methods, the Relative Percentage Error (RPE) test can be used. The equation of RPE test is given in the following equation [24]:

$$
\mathrm{RPE}=\left[\frac{P_{W}-P_{M}}{P_{M}}\right] * 100 .
$$

The RPE statistical results of all methods for five years are given in Table 4 .

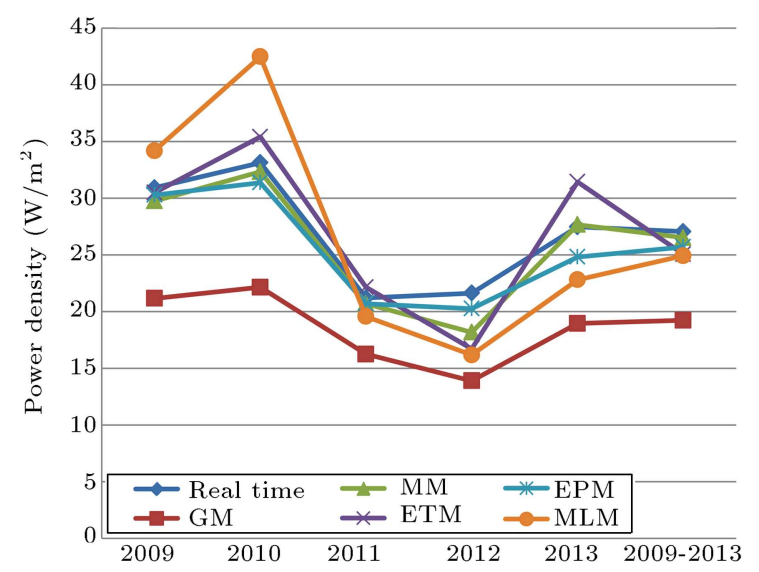

Figure 14. The wind power density for all used methods.

If we generally evaluate the results, the best results are obtained by Energy Pattern Method and the worst ones are obtained by Graphical Methods for a five-year period. According to all obtained results, the more appropriate estimation method is not identical for all years. For 2009, the Energy Trend Method determined more effective estimation methods of Weibull parameters to compute the wind power density. For 2011, the Moment Method determined more effective estimation methods of Weibull parameters to compute the wind power density.

Table 4. The RPE statistical error analysis for all used methods.

\begin{tabular}{cccccc}
\hline RPE test & GM & MM & ETM & EPM & MLM \\
\hline 2009 & -31.5755419 & -3.785182789 & -1.391135555 & -2.070527337 & 10.54674863 \\
2010 & -33.15217391 & -2.415458937 & 6.884057971 & -5.314009662 & 28.23067633 \\
2011 & -23.40726758 & -1.086956522 & 4.483246815 & -2.359603587 & -28.76911872 \\
2012 & -35.75393154 & -15.95744681 & -22.71045328 & -6.336725254 & -25.25439408 \\
2013 & -31.02694829 & 0.728332119 & -31.02694829 & -9.650400583 & -16.97013838 \\
\hline
\end{tabular}




\section{Conclusions}

In this study, by using the available wind data, the reliability and quality of wind speed for Osmaniye region were evaluated, and the values of Weibull parameters ' $k$ ' and ' $c$ ' were determined by using different kinds of estimation methods. The obtained results show that the frequency and density of wind speed within $10 \mathrm{~m}$ height is at a sufficient level. This study is a preliminary study for the determination of wind potential before making an investment in wind energy for one region. We have examined the coherence of wind speeds with the Weibull distribution function by using wind speed data for the years 2009 to 2013. The present study is a pre-research conducted for predicting the wind energy analysis of Osmaniye region. According to test results of the Relative Percentage Error (RPE), GM's performance in estimating Weibull parameters is the worst one, and the best parameter estimation is accomplished by using EPM. Moreover, this study can give useful insights for the investors in Osmaniye Region to deal with wind energy. In future studies, the scope of this study can be expanded and detailed to determine the wind energy potential of Osmaniye Region.

\section{References}

1. Esteves, N.B., Sigal, A., Leiva, E.P.M., Rodríguez, C.R., Cavalcante, F.S.A. and de Lima, L.C. "Wind and solar hydrogen for the potential production of ammonia in the state of Ceara Brazil", International Journal of Hydrogen Energy, 40, pp. 9917-9923 (2015).

2. Fan, H., Singh, R. and Akbarzadeh, A. "Lectric power generation from thermoelectric cells using a solar dish concentrator", J. Electron. Mater., 40, pp. 1311-1320 (2011).

3. Kaplan, Y.A. "Overview of wind energy in the world and assessment of current wind energy policies in Turkey", Renewable and Sustainable Energy Reviews, 43(C), pp. 562-568 (2015).

4. Kaplan, Y.A. and San, I. "Current situation of wind energy in the world and Turkey", Green Energy Conference-VI (IGEC-VI), Eskisehir, Turkey (2011).

5. Ghaedi, A., Abbaspour, A., Fotuhi-Firuzabad, M. and Parvania, M. "Incorporating large photovoltaic farms in power generation system adequacy assessment", $J$. Sci. Iran., 21(3), pp. 924-934 (2014).

6. Roy, G., Matagne, E. and Jacques, P.J. "A global design approach for large-scale thermoelectric energy harvesting systems", J. Electron. Mater., 42, pp. 17811788 (2013).

7. Çapika, M., Yılmaz, A.O. and Çavusoglu, I. "Present situation and potential role of renewable energy in Turkey", Renewable Energy, 46, pp. 1-13 (2012).
8. Gabbasa, M., Sopian, K., Yaakob, Z., Zonooz, M., Fudholi, A. and Asim, N. "Review of the energy supply status for sustainable development in the Organization of Islamic Conference", Renewable and Sustainable Energy Reviews, 28, pp. 18-28 (2013).

9. Zerhounia, F.Z., Zerhounia, M.H., Zegrara, M., Benmessaouda, M.T, Tilmatineb, A. and Boudghene Stamboulia, A. "Modelling polycristallin photovoltaic cells using design of experiments", J. Sci. Iran., 21(6), pp. 2273-2279 (2014).

10. Kantar, Y.M. and Usta, I. "Analysis of wind speed distributions: wind distribution function derived from minimum cross entropy principles as better alternative to Weibull function", Energy Convers Manage, 49, pp. 962-973 (2008).

11. Akda ğ, S.A. and Dinler, A. "A new method to estimate Weibull parameters for wind energy applications", Energy Convers Manag, 50, pp. 1761-1766 (2009).

12. Bilgili, M. and ve Şahin, B. "The finding of Weibull parameters at the determination of Wind Power density", New and Renewable Energy/Energy Management Symposium, Kayseri, pp. 229-234 (2005).

13. Rocha, P.A.C.R., Sousa, R.C.D., Andrade, C.F.D. and Silva, M.E.V.D. "Comparison of seven numerical methods for determining Weibull parameters for wind energy generation in the northeast region of Brazil", Applied Energy, 89, pp. 395-400 (2012).

14. Freitas de Andrade, C., Maia Neto, H.F., Costa Rocha, P.A. and Vieira da Silva, M.E. "An efficiency comparison of numerical methods for determining Weibull parameters for wind energy applications: A new approach applied to the northeast region of Brazil", Energy Convers Manage, 86(10) pp. 801-808 (2014).

15. Chang, T.P. "Performance comparison of six numerical methods in estimating Weibull parameters for wind energy application", Appl. Energy., 88, pp. 272-282 (2011).

16. Bilir, Levent, et al. "Seasonal and yearly wind speed distribution and wind power density analysis based on Weibull distribution function", International Journal of Hydrogen Energy, 40(44), pp. 15301-15310 (2015).

17. Yaniktepe, B., Koroglu, T. and Savrun, M.M. "Investigation of wind characteristics and wind energy potential in Osmaniye, Turkey", Renewable and Sustainable Energy Reviews, 21, pp. 703-711 (2013).

18. Kım, J.S. and Yum, B.J. "Selection between ewibull and lognormal distributions: A comparative simulation study", Computational Statistics \& Data Analysis, 53(2), pp. 477-485 (2008).

19. Azad, A.K., Rasul, M.G. and Yusaf, T. "Statistical diagnosis of the best Weibull methods for wind power assessment for agricultural applications", Energies, 7, pp. 3056-3085 (2014). 
20. Morgan, E.C., Lackner, M., Vogal, R.M. and Baise, L.G. "Probability distributions of offshore wind speeds", Energy Conversion and Management, 52, pp. 15-26 (2011).

21. Yıldırım, U., Gazibey, Y. and Güngör, A. "Wind Energy Potential of Niğde", Journal of Niğde University, 1(2), pp. 37-47 (2012).

22. Kose, R., Arif, M.O., Erbas, O. and Tugcu, A. "The analysis of wind data and wind energy potential in Kutahya, Turkey", Renewable and Sustainable Energy Reviews, 8, pp. 277-288 (2004).

23. Gokcek, M., Bayulken, A. and Bekdemir, S. "Investigation of wind characteristics and wind energy potential in Kirklareli, Turkey", Renewable Energy, 32, pp. 1739-1752 (2007).
24. Sabzpooshani, M. and Mohammadi, K. "Establishing new empirical models for predicting monthly mean horizontal diffuse solar radiation in city of Isfahan, Iran", Energy, 69(5), pp. 71-77 (2014).

\section{Biography}

Yusuf Alper Kaplan is an Assistant Professor in Energy Engineering Department of Osmaniye Korkut Ata University, Osmaniye, Turkey. He received his $\mathrm{PhD}$ degree in Electrical and Electronics Engineering from Anadolu University, Eskişehir, Turkey, in 2014. His main research interests are renewable energy, wind energy, solar energy, and power quality. 